\title{
Baixada Fluminense, uma Periferia por Excelência
}

\author{
Baixada Fluminense, Periphery of Excellence
}

Baixada Fluminense, Periferia de Excelencia

Enderson Alceu Alves Albuquerque ${ }^{1}$

https://orcid.org/ 0000-0001-7807-1851

\begin{abstract}
RESUMO: O presente trabalho tem por objetivo analisar o processo de adensamento populacional da Baixada Fluminense como emblema para o processo de construção de uma periferia por excelência (CORRÊA, 2011), no contexto fluminense. Para atingir esse propósito, analisamos a dinâmica populacional dos municípios baixadianos no interior da Região Metropolitana do Rio de Janeiro (RMRJ). Os resultados apontaram que o setor imobiliário reservou a Baixada Fluminense para a população de baixo status social e, por essa razão, essa sub-região metropolitana é constantemente preterida nas políticas públicas executadas na metrópole na qual está inserida. Com efeito, no imaginário social a Baixada Fluminense é atrelada a aspectos relacionados a atrasos sociais como a pobreza, as carências infra estruturais e, sobretudo, a violência.
\end{abstract}

PALAVRAS-CHAVE: Baixada Fluminense. Região Metropolitana do Rio de Janeiro. Periferia.

ABSTRACT: The present work aims to analyze the population densification process of the Baixada Fluminense as an emblem for the process of building a periphery par excellence (CORREA, 2011) in the Rio de Janeiro context. To achieve this purpose, we analyzed the population dynamics of the cities in the interior of the metropolitan region of Rio de Janeiro (RMRJ). The results showed that the real estate sector reserved the Baixada Fluminense for the population with low social status and for this reason, this metropolitan sub-region is constantly neglected in public policies carried out in the metropolis in which it operates. Indeed, in the social imagination, Baixada Fluminense is linked to aspects related to social backwardness such as poverty, infrastructural deficiencies and, above all, violence.

KEYWORDS: Baixada Fluminense. Metropolitan Region of Rio de Janeiro. Periphery.

RESUMEN: El presente trabajo tiene como objetivo analizar el proceso de densificación de la población de la Baixada Fluminense como emblema del proceso de construcción de una periferia por excelencia (CORREAA, 2011) en el contexto de Río de Janeiro. Para lograr este propósito, analizamos la dinámica de la población de las ciudades del interior de la región metropolitana de Río de Janeiro (RMRJ). Los resultados mostraron que el sector inmobiliario reservó la Baixada Fluminense para la población con bajo estatus social y por esta razón, esta subregión metropolitana se descuida constantemente en las políticas públicas llevadas a cabo en la metrópoli en la que opera. De hecho,

\footnotetext{
${ }^{1}$ Doutor pelo Programa de Pós-Graduação em Geografia/ UERJ. Professor regente em escolas municipais do Rio de Janeiro e de Mesquita. E-mail: endersonalbuquerque@yahoo.com.br.
} 
en la imaginación social, Baixada Fluminense está vinculada a aspectos relacionados con el atraso social, como la pobreza, las deficiencias de infraestructura y, sobre todo, la violencia.

PALABRAS CLAVE: Baixada Fluminense. Región Metropolitana de Rio de Janeiro. Periferia.

\section{INTRODUÇÃO}

Os municípios da Baixada Fluminense tiveram seu processo de ocupação populacional atrelado à expansão fundiária do então Distrito Federal e sua dinâmica econômica. Mesmo após a transferência da capital do país para Brasília em 1960 e posterior criação da Região Metropolitana do Rio de Janeiro (RMRJ) continuou vinculada ao município do Rio de Janeiro. Em consonância ao projeto nacional, na década de 1970 a Baixada Fluminense apresentou um acelerado processo de urbanização, materializado juridicamente com a criação da Região Metropolitana do Rio de Janeiro em 1973.

A área metropolitana fluminense nasceu formada por dois estatutos jurídicos distintos, o do Estado da Guanabara e o do Estado do Rio de Janeiro. Em virtude dessas condições, a região expressa de forma cristalina sua condição periférica no bojo da RMRJ. Com efeito, a Baixada Fluminense se inscreve como integrante periférica da área metropolitana fluminense, conforme ilustra a Figura 1.

Figura 1 - Municípios componentes da Baixada Fluminense e da Região Metropolitana do Rio de Janeiro

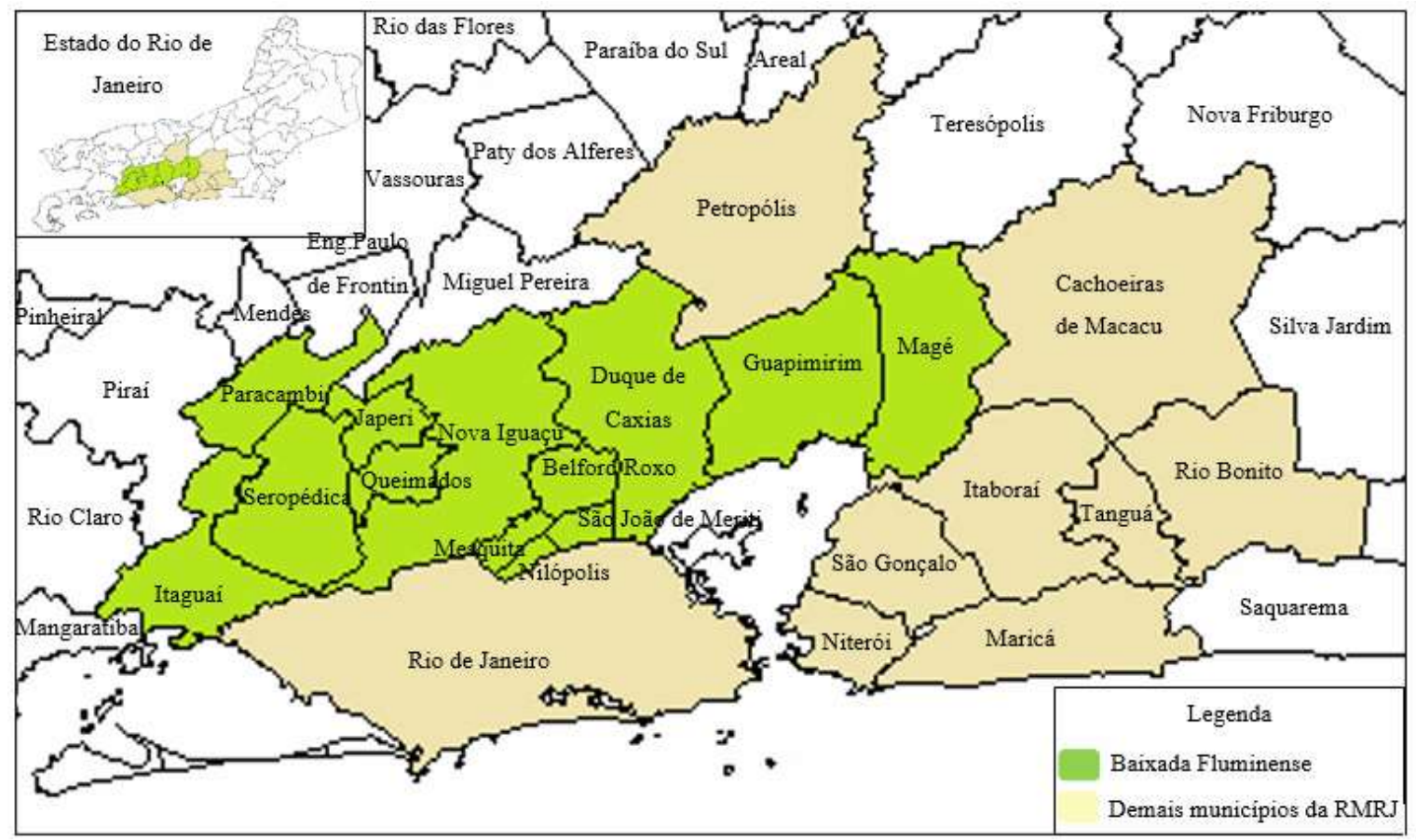

Fonte: elaborado pelo autor (2020). 
Tal condição periférica se expressa, também, no perfil socioeconômico de sua população e, de maneira mais perversa, nas políticas públicas destinadas aos municípios que a compõem. Assim, este artigo almeja relacionar a lógica ocupacional da RMRJ à periferização da Baixada Fluminense tendo como recorte temporal os anos de 1950, início do adensamento mais efetivo da região, até o presente momento. $O$ artigo se divide em duas partes. Na primeira parte analisamos o processo histórico de formação populacional da supracitada região e na segunda estudamos o processo de periferização da citada região e suas implicações materiais e simbólicas.

\section{O ADENSAMENTO POPULACIONAL DA BAIXADA fLUMINENSE A PARTIR DOS LOTEAMENTOS}

No início do governo republicano no Brasil, um considerável ponto de inflexão para o desenvolvimento social da Baixada Fluminense ocorreu durante a gestão federal de Nilo Peçanha (1909 a 1910). Nesse período, a economia brasileira se caracterizava por seu modelo agroexportador, de tal sorte que os produtos primários compunham uma expressiva parcela do Produto Interno Bruto (PIB) nacional. Apostando na "vocação agrícola" da Baixada Fluminense nesse cenário, Nilo Peçanha, que assumiu a presidência da República com a morte do presidente eleito Afonso Pena, instituiu a Primeira Comissão Federal de Saneamento para a Baixada Fluminense em 1910. Nesse sentido, para Lamego (1964, p. 277),

[...] a solução do problema da Baixada e especialmente o do recôncavo da Guanabara justaposto ao Rio de Janeiro, de ocupação imediata, só se tornaria definitiva quando a par de vultosas cifras aplicadas em engenharia hidráulica e sanitária, paralelamente se alinhassem dados complementares de estudos para um intenso povoamento, com a presença do homem não mais em tarefas individualistas, mas coletivamente orientado por um órgão oficial e fiscalizador das suas atividades e que lhe garantisse um patrimônio arrancado aos lamaçais. E isto, foi somente compreendido e pela primeira vez iniciado em grande escala pelo Departamento Nacional de Obras de Saneamento criado pelo Governo.

Para assumir sua "vocação agrícola", a Baixada Fluminense necessitava sanar as constantes inundações que a assolavam. Sobre esta questão, para o engenheiro responsável pela comissão de saneamento,

[...] deixando de lado o trecho marítimo inferior, onde os transbordamentos provêm da oscilação da maré, apontam-se as seguintes causas: 1) constituição geológica; 2) configuração topográfica; 3) chuvas; 4) a insuficiências das secções de vazão dos rios e 5) as estradas de ferros e rodagem (GÓES, 1934, p. 17). 
Além das características físico-naturais, Góes aponta a interferência humana como um fator responsável pelas inundações da região, pois as ferrovias e algumas rodovias agiam como barreiras para o escoamento das águas pluviais. Contudo, de acordo com Souto (2016, p. 61), essas intervenções não se limitaram às questões de saneamento. Para a autora,

[...] o objetivo da Comissão era desapropriar, sanear, repartir em pequenas propriedades e vender os terrenos. Desta forma o retorno seria praticamente imediato ao fim das obras, talvez tenha sido esse um dos argumentos utilizados por Nilo Peçanha no convencimento da liberação de verbas para a continuidade dos trabalhos da Comissão. Outra forma de ocupar os espaços dessecados era através da fundação de colônias ou núcleos agrícolas defendidos por Nilo Peçanha na seção colonização de sua mensagem presidencial de 1910. (SOUTO, 2016, p. 61).

A intenção de ocupação populacional do espaço baixadiano por meio da Comissão de Saneamento é reforçada por Lamego (1964), o qual entendia que tal intervenção objetivava criar infraestrutura capaz de absorver a futura demanda habitacional da área. Além de expandir as áreas de lavouras da Baixada Fluminense e iniciar a "colonização" da região, essas comissões almejavam diminuir os índices de doenças na mesma, como a malária, que vitimou $10 \%$ dos trabalhadores da primeira comissão de saneamento (SOUTO, 2016). Quanto ao intento governamental de intensificar a ocupação populacional da região no início do século, esse processo se aguçou somente com a instauração da Segunda Comissão Federal de Saneamento, em 1933. Com efeito, para Segadas Soares (1962, p. 173), a política de saneamento na Baixada Fluminense colocou:

[...] à disposição dos capitais da metrópole vizinha, grandes unidades fundiárias que facilitavam certos tipos de empreendimentos, dentre eles os loteamentos. As necessidades de moradia de uma população, que crescia rapidamente, assim como a extraordinária desvalorização da moeda, levando a população da metrópole à prática generalizada de aplicar suas pequenas economias na compra de lotes nessa área, aliadas às facilidades proporcionadas pela rede de estradas da região foram fatores do enorme êxito desse tipo de empreendimento e da extraordinária valorização das terras da baixada.

Em paralelo a esse processo, a prefeitura do Rio de Janeiro passou a elaborar medidas mais restritivas à ocupação do solo, além de aumentar a repressão às favelas, como alude Simões (2008). Desse modo, a partir da década de 1930 houve a intensificação do loteamento de terras na Baixada Fluminense, conforme registram os gráficos a seguir (Figura 2).

O recorte temporal contemplado pelos gráficos indica um processo inicialmente pouco expressivo entre 1929 e 1939 no número de lotes e loteamentos. O incremento populacional 
verificado nesse período foi obtido "Mediante a multiplicação de propriedades aptas à lavoura citricultora, em especial entre os períodos de 1920 a 1940, quando se tem um aumento populacional na área rural, decorrente do fluxo de mão-de-obra utilizada, incluindose assalariados, meeiros e lavradores" (FIGUERÊDO, 2004).

Figura 2 - Gráficos da evolução dos números de lotes e loteamentos na Baixada Fluminense (1929 - 1969)

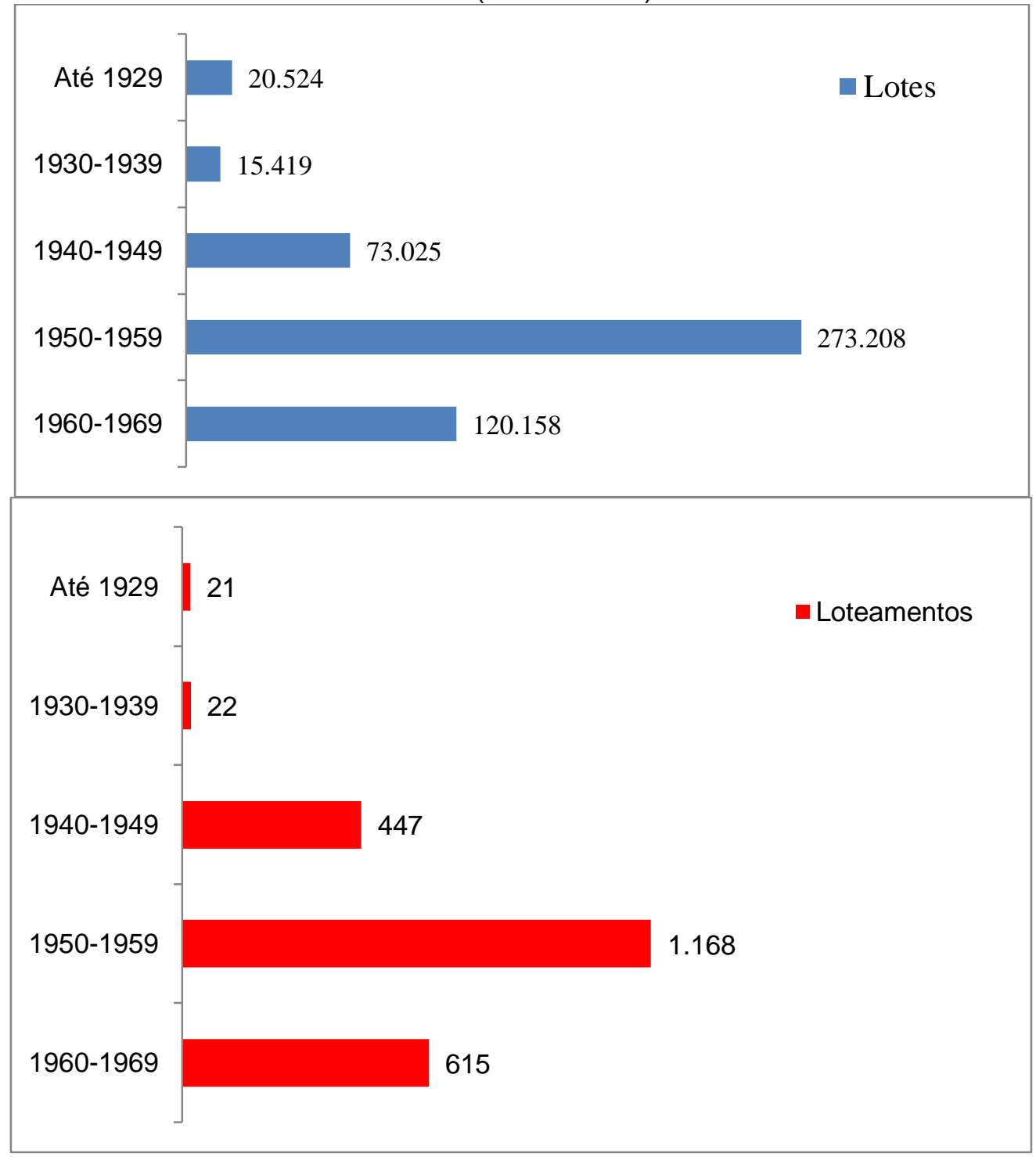

Fonte: Alves (2003).

Essa dinâmica foi posteriormente substituída por uma elevação considerável no número de lotes e loteamentos, entre 1940 e 1959. Analisando esse processo no referido recorte espacial, a fundação responsável pelo desenvolvimento da RMRJ concluíra que,

[...] a ocupação urbana da Baixada Fluminense, dependente em primeira instância do transporte ferroviário, se deu inicialmente nas áreas de maior proximidade da massa urbana da metrópole e em torno das estações, dando origem aos atuais centros, enquanto os loteamentos, a partir do final 
da década de 40 se dão indiscriminadamente por todo o território (FUNDAÇÃO PARA O DESENVOLVIMENTO DA REGIÃO METROPOLITANA DO RIO DE JANEIRO, 1979, p. 26).

$\mathrm{Na}$ década de 1950, os grandes promotores fundiários eram figuras de destaque político, sendo denominados os "bandeirantes da Baixada Fluminense" (HOMENAGEADO ..., 1951, p. 6). A despeito do processo de adensamento populacional vivenciado pelos municípios baixadianos, as políticas públicas do período ainda enxergavam a região como celeiro alimentar, de modo que ações privadas visavam promover o uso agrícola da Baixada Fluminense.

Em 1952, um grupo de empresários criou a Agrinco do Brasil S.A, companhia que se dizia preocupada com o êxodo rural "[...] para os grandes centros urbanos que resulta não apenas em um abandono por parte do lavrador de suas funções, como principalmente pelo desaparecimento de capital nas zonas de produção agrícola" (VALORIZAÇÃO..., 1952, p. 7). Ainda de acordo com a reportagem, a empresa já havia adquirido propriedades na Baixada Fluminense para o plantio de "laranjeiras, abacateiros, sapotizeiros, aipim e batata". $O$ arquétipo da Baixada Fluminense como área rural está expresso no título da citada reportagem: "Valorização e aproveitamento do campo para a salvação das cidades! ". Assim, apesar de a década de 1950 registrar o maior incremento em número de lotes e loteamentos, a visão agrícola da região ainda persistia.

Todavia, em decorrência da eclosão da Segunda Guerra Mundial, visto que seu produto era altamente dependente do mercado externo, e em associação às deficientes infraestruturas de circulação, a atividade agrícola, notadamente a citricultura, passou por uma crise. Frente a esse quadro, a solução encontrada por partes dos proprietários de fazenda foi fracionar as terras para loteamentos. Nesse período, com o propósito de criar infraestrutura adequada para loteamentos, empresas imobiliárias ofereciam serviços aos fazendeiros por meio de anúncios em periódicos de grande circulação, e latifundiários ofertavam seus terrenos para empresas loteadoras interessadas em grandes áreas para fins residenciais (Figura 3).

Por esta razão, a autoconstrução, à revelia de uma correspondência infra estrutural por parte do Estado, foi o padrão de construção urbana na Baixada Fluminense e, desse modo, de acordo com a (FUNDREM) Fundação para o Desenvolvimento da Região Metropolitana do Rio De Janeiro (1979, p. 27), "[...] em nenhum momento do processo de ocupação da Baixada pôde-se verificar um comportamento saudável do mercado imobiliário".

A conformação entre promotores fundiários e promotores imobiliários aludida pela Figura 3 responde pelo crescimento expressivo do número de lotes e loteamentos na região entre as décadas de 1940 e 1950. Posteriormente, a partir de 1960, esse movimento foi 
seguido por uma diminuição. A queda nos números absolutos de lotes e loteamentos consiste em um dado natural, em virtude da ocupação das áreas livres. Desse modo, a menor oferta de lotes sugere, em alguma medida, o adensamento demográfico da área. Desta maneira, o espaço de tempo aludido nos gráficos acima retrata distintas dinâmicas quanto ao processo de ocupação territorial da Baixada Fluminense.

Figura 3 - Anúncios de companhia imobiliária e latifundiários nas décadas de 1940 e 1950

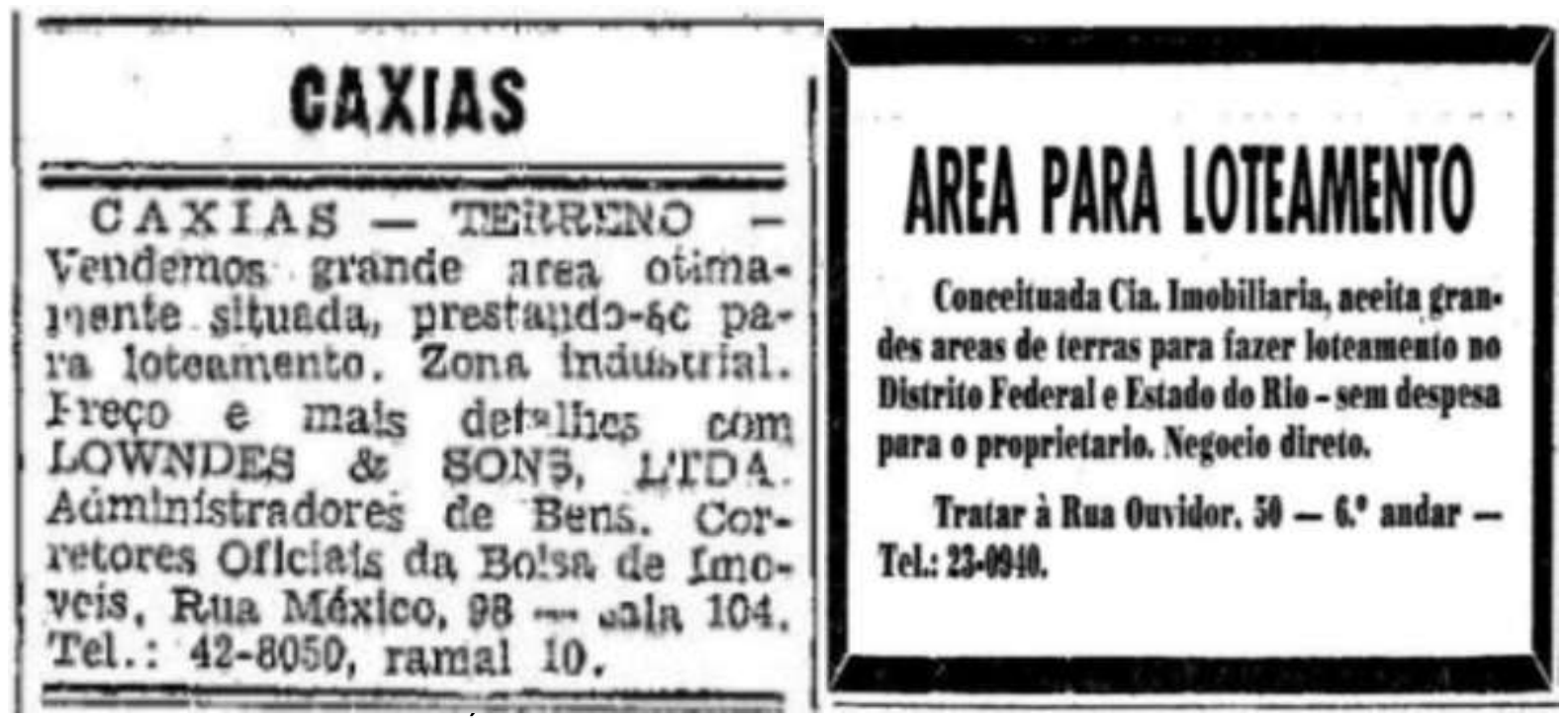

Fonte: Mercado ... (1945) e Área... (1953).

Já na primeira metade da década de 1970 a comercialização dos lotes apresentou um período de queda acentuada. O Jornal do Brasil do ano de 1973 registrou em uma de suas edições a seguinte manchete: "Crise de mercado atinge loteamentos da Baixada". A publicação explicava que "[...] o aumento de preços dos materiais de construção e o excesso de loteamentos - oferta maior que a procura" seriam as principais causas para o desaquecimento das vendas no município de Nova Iguaçu. Em seguida, o texto conclui que "[...] de 'bom negócio' há alguns anos passados, como se referem ao assunto alguns corretores, a venda de terrenos no município passou a ser disputada palmo a palmo pelas imobiliárias" e, em decorrência desta conjuntura, "[...] a oferta de prêmios em dinheiro a quem apresentar compradores e a propaganda de lotes através de panfletos e automóveis nas ruas são os sinais dessa disputa e dessa crise". (CRISE..., 1973, p. 1). A Figura 4 alude para as estratégias desse setor para atrair novos compradores.

A infraestrutura fornecida pelo Estado e a criação de ligação ferroviária com a capital possibilitaram a incorporação de parte da região à mancha urbana da cidade do Rio de Janeiro, como apontam, entre outros, Segadas Soares (1962) e Abreu (2010), e também influíram no preço dos loteamentos. Nesse momento, de acordo com Pacheco (1984, p. 17), o capital imobiliário: 
[...] favoreceu o crescimento descontínuo do espaço metropolitano, na medida em que reservou terrenos mais próximos às áreas centrais com o intuito de esperar sua valorização, ao passo que áreas longínquas, além dos limites do então Distrito Federal, foram oferecidas à população de baixa renda, sem a necessária infra-estrutura urbana. É desse modo que desponta e se institucionaliza a periferia como habitat dessas populações pobres: atendendo aos interesses imobiliários.

Figura 4 - Estratégias de vendas dos promotores fundiários para atrair compradores para os lotes iguaçuanos na década de 1970
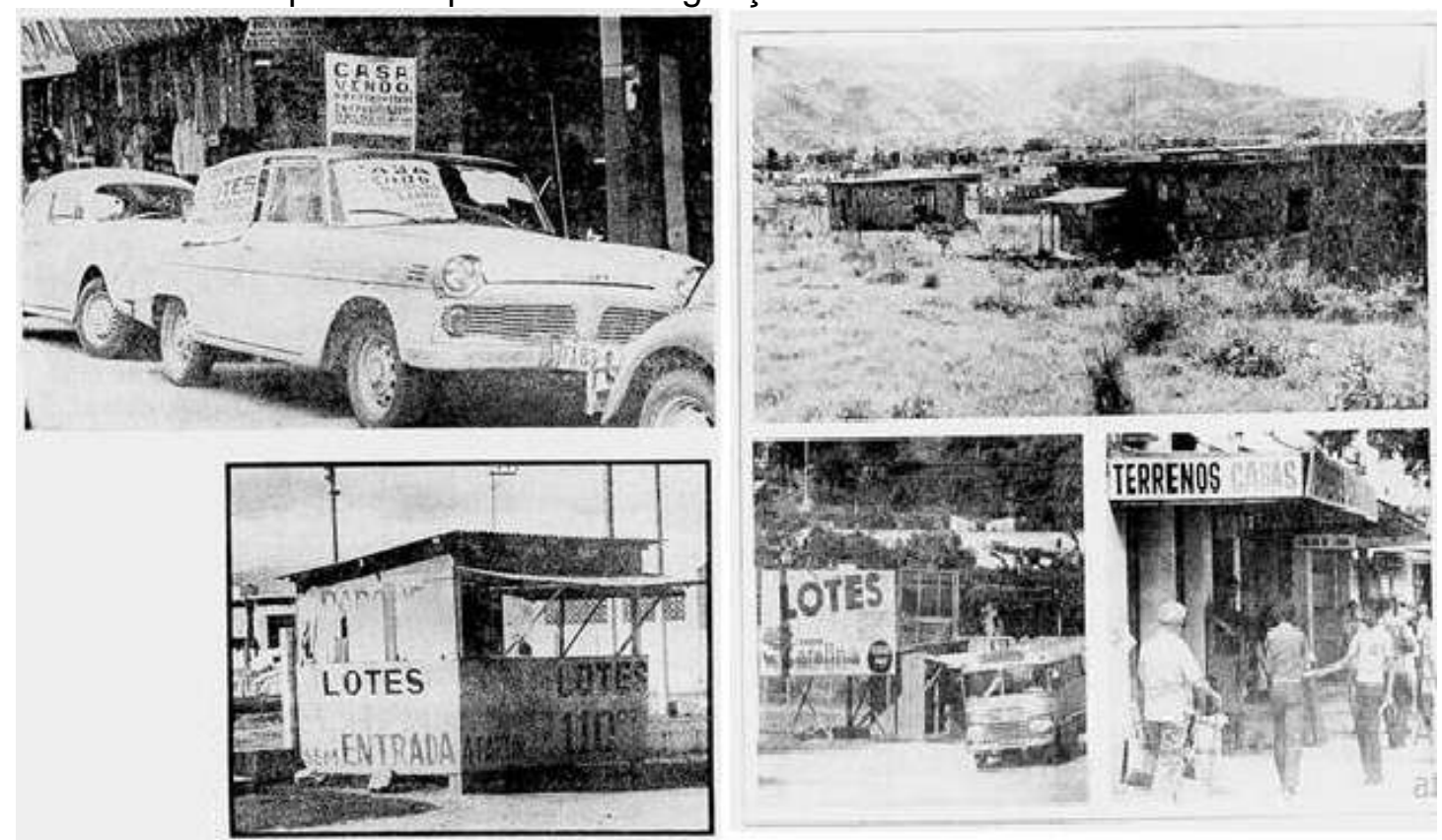

Fonte: Crise ... (1973).

Em razão do quadro mencionado pela autora, a Baixada Fluminense foi destinada à população de menor poder aquisitivo. Essa política, empreendida pelos proprietários fundiários e pelos promotores imobiliários com o consentimento do Estado, expulsou o trabalhador das áreas mais próximas ao núcleo metropolitano. Entretanto, o afastamento físico não impossibilitou a absorção da mão-de-obra para as atividades localizadas na área central. Por essa lógica geográfica, o capital fundiário se beneficiou com a venda dos terrenos periféricos da Baixada Fluminense e o capital industrial manteve o trabalhador relativamente próximo ao local de trabalho.

Esta estratégia evidencia que a dinâmica demográfica e econômica da Baixada Fluminense, particularmente neste recorte temporal, refletia em larga medida as demandas do município do Rio de Janeiro. Sobre esta questão, Segadas Soares (1962, p. 176) observa que a Baixada Fluminense:

[...] é o complemento natural da cidade do Rio de Janeiro que, se nasceu em uma de suas extremidades, parece ter sido para melhor zelar por esse 
conjunto integrado pela Guanabara e seu recôncavo. Constituiu este a primeira área sobre a qual a cidade exerceu a sua influência, foi o seu primeiro hinterland, a sua primeira região urbana, isto é, foi aquela área dentro da qual a urbe exerceu, desde os primórdios da colonização, predominância econômica e cultural.

Por esta linha de raciocínio, as transformações socioeconômicas promovidas no núcleo repercutiram na periferia baixadiana, como a Reforma Pereira Passos a partir de 1903. Não se pode afirmar que essa reforma urbanística tenha alimentado imediatamente o incremento populacional na Baixada Fluminense, contudo pode-se inferir que a população expulsa da área central da cidade ocupou áreas pouco valorizadas do mesmo município. Como os morros ao redor da área central foram ocupados pela população anteriormente residente do centro da cidade, parte dos migrantes oriunda de Minas Gerais, Espírito Santo e de estados nordestinos passou a se dirigir para os municípios baixadianos. Por essa razão, não no período imediato de sua execução, a Reforma Passos concorreu, em alguma medida, para o processo de adensamento populacional da Baixada Fluminense.

Assim, "[...] surgia nesse momento um novo padrão de produção do espaço construído urbano, os chamados 'loteamentos periféricos', que mudaria, doravante, a forma e o conteúdo não apenas do Rio de Janeiro, mas das demais grandes cidades brasileiras" (LAGO, 2000, p. 67). Esse rearranjo imobiliário se manifestou por meio do adensamento demográfico dos municípios vizinhos ao Rio de Janeiro, conforme atesta a Tabela 1.

Considerando a população relativa e em comparação com o município do Rio de Janeiro, à qual sua dinâmica socioeconômica estava fortemente vinculada no período compreendido entre as décadas de 1920 e 1960, a Baixada Fluminense apresentou taxa de adensamento populacional mais expressiva que o núcleo metropolitano, conforme expõe a Tabela 2.

Como comparativo, enquanto a Baixada Fluminense apresentou uma taxa de crescimento populacional superior a 2.000\% entre 1920 e 1960, no município do Rio de Janeiro esse crescimento foi de cerca de 190\%, passando de um pouco menos de 1 hab./km² em 1920 para 2,75 hab./km² em 1960. Parte da explicação dessa disparidade se deve ao processo de ocupação das referidas áreas. Na condição de capital do país, o Rio de Janeiro já possuía população elevada para a realidade brasileira em 1920. Em 1960, o município fluminense perdeu o posto de maior cidade do Brasil para São Paulo e a função de capital para Brasília. Esses fatores indicam que o período contemplado pela tabela parte de uma década de apogeu demográfico carioca e encerra com uma década de diminuição de importância política, a qual pode ter influenciado no menor crescimento populacional do município. A área territorial ocupada pelos dois recortes espaciais citados também ajuda a explicar os números apontados 
Tabela 1 - Evolução da população absoluta dos municípios da Baixada Fluminense (19502010) - Censos Demográficos do IBGE

\begin{tabular}{|c|c|c|c|c|c|c|c|c|}
\hline \multirow{2}{*}{ Municípios } & \multicolumn{7}{|c|}{ Censos Demográficos } & \multirow{2}{*}{ Variação } \\
\hline & 1950 & 1960 & \begin{tabular}{|l|}
1970 \\
\end{tabular} & 1980 & 1991 & 2000 & 2010 & \\
\hline Belford Roxo & & & & & 360.699 & 434.474 & 469.261 & $30,0 \%$ \\
\hline $\begin{array}{l}\text { Duque de } \\
\text { Caxias }\end{array}$ & 92.459 & 241.026 & 431.397 & 575.830 & 667.821 & 775.456 & 855.046 & $824,7 \%$ \\
\hline Guapimirim & & & & 28.076 & 28.076 & 37.920 & 51.483 & $83,3 \%$ \\
\hline Itaguaí & 29.566 & 44.100 & 55.839 & 90.131 & 113.057 & 82.003 & 109.163 & $269,2 \%$ \\
\hline Japeri & & & & & 65.783 & 83.209 & 95.492 & $45,1 \%$ \\
\hline Magé & 36.761 & 58.353 & 113.023 & 166.603 & 191.734 & 205.830 & 228.150 & $520,6 \%$ \\
\hline Mesquita & & & & & & 167.272 & 168.403 & $0,6 \%$ \\
\hline Nilópolis & 46.406 & 95.111 & 128.011 & 151.585 & 158.092 & 153.712 & 157.483 & $239,3 \%$ \\
\hline Nova Iguaçu & 145.649 & 356.645 & 727.14 & $\begin{array}{r}1.094 .78 \\
9\end{array}$ & 772.399 & 753.327 & 795.212 & $445,9 \%$ \\
\hline Paracambi & & & 25.368 & 30.310 & 36.427 & 40.441 & 47.124 & $85,7 \%$ \\
\hline Queimados & & & & & 98.823 & 121.993 & 137.938 & $39,5 \%$ \\
\hline $\begin{array}{l}\text { São João de } \\
\text { Meriti }\end{array}$ & 76.462 & 190.516 & 302.394 & 398.819 & 425.772 & 449.476 & 459.356 & $500,7 \%$ \\
\hline Seropédica & & & & & 49.663 & 65.206 & 78.186 & $57,4 \%$ \\
\hline $\begin{array}{l}\text { Baixada } \\
\text { Fluminense }\end{array}$ & 427.303 & 985.751 & 1.783 .172 & 2.508 .067 & 3.038 .085 & $\begin{array}{r}3.367 .70 \\
6\end{array}$ & $\begin{array}{r}3.652 .14 \\
7\end{array}$ & $754,6 \%$ \\
\hline
\end{tabular}

Tabela 2 - Evolução da densidade demográfica: Rio de Janeiro e Baixada Fluminense (1920-1960)

\begin{tabular}{l|r|r}
\hline \multirow{2}{*}{ Ano } & \multicolumn{3}{|c}{ Densidade demográfica hab./km ${ }^{2}$} \\
\cline { 2 - 4 } & Rio de Janeiro & Baixada Fluminense \\
\hline 1920 & 0,95 & 0,016 \\
1940 & 1,46 & 0,06 \\
1950 & 1,98 & 0,15 \\
1960 & 2,75 & 0,35 \\
\hline
\end{tabular}

Taxa de crescimento

$189,5 \%$

$2.087,5 \%$

Fonte: IBGE (1920, 1940, 1950, 1960).

A Baixada Fluminense em 1920 apresentava "vocação" eminentemente agrícola. Com população inferior a 50 mil habitantes nesta década, 40 anos depois a região totalizava quase um milhão de residentes. Por este motivo, a densidade demográfica apurada para este intervalo de tempo em território baixadiano se inicia com um povoamento pouco expressivo e se encerra registrando um período no qual o processo de conversão no uso da 
terra nos municípios estava se consolidando. Esta distinção explicaria a disparidade quanto ao aumento da densidade demográfica no comparativo entre o município do Rio de Janeiro e a Baixada Fluminense. Todavia, tais números, apesar destas ponderações, implicam em constatar que neste período a Baixada Fluminense apresentou adensamento populacional mais intenso, sobretudo em virtude dos loteamentos.

O loteamento do território baixadiano se favoreceu ainda de outras intervenções infra estruturais promovidas pelo Estado. Entre elas, Alves (2003, p. 63) destaca "[...] a eletrificação da Estrada de Ferro Central do Brasil, a partir de 1935; a tarifa ferroviária única no Grande Rio; a construção da avenida Brasil, em 1946; a criação do Serviço de Malárias da Baixada Fluminense, em 1947; e a abertura da rodovia Presidente Dutra, em 1951". O capital privado, em decorrência do surto industrial pelo qual passou a Baixada Fluminense a partir da década de 1950, também atuou para o processo de adensamento populacional da região. Desse período datam a instalação da indústria farmacêutica Bayer em Belford Roxo e da Fábrica Nacional de Motores e da Refinaria de Petróleo de Duque de Caxias (ROCHA, 2009).

Na década de 1970, precisamente em 1974, a relação entre a Baixada Fluminense e o município do Rio de Janeiro se alterou juridicamente com a fusão dos estados da Guanabara e do Rio de Janeiro. Contudo, pelo fato de ter sido capital da República por um longo período, a cidade carioca acumulou em seu espaço infraestrutura, diferentemente das áreas ao seu redor. Sobre esse período, Abreu (2010, p. 17-18) assinala que:

[...] a antiga situação, em que o núcleo se via separado de suas periferias e do seu território com a divisão da Região Metropolitana em dois estados, contribuiu ainda para reforçar sobremaneira a dicotomia núcleo/periferia. A cidade do Rio de Janeiro, e mais especificamente o seu núcleo, concentrou todos os recursos, muitas vezes aplicando em obras suntuosas e de prestígio, sem reinvestir nada numa região onde não tinha responsabilidades políticas. O resultado foi um núcleo forte, cercado por uma periferia pobre e superpovoada, onde eram deixados todos os ônus para o antigo Estado do Rio, enquanto a Guanabara auferia todas as vantagens disponíveis.

Pela razão mencionada, a instituição da RMRJ evidenciou a dissonância existente entre seu núcleo, o município do Rio de Janeiro, e sua periferia intermediária, como convencionou chamar Abreu (2010), a Baixada Fluminense. Sobre essa relação, Corrêa (2011, p. 160-161) entende que "[...] a periferia da metrópole é o lugar de existência e reprodução de parcela ponderável das camadas populares. No caso da metrópole carioca, esta periferia é conhecida, sobretudo como a Baixada Fluminense", a qual, por sua vez, consiste na "[...] justaposição de numerosos loteamentos, que acabam formando um mosaico irregular, cujo conteúdo em termos de equipamentos de consumo coletivo é extremamente precário" (CORRÊA, 2011, p. 161). Sobre a condição periférica baixadiana, 
considerando seus desdobramentos socioeconômicos e simbólicos, se dedica a parte seguinte deste artigo.

\section{A CONSTRUÇÃO DA PERIFERIA BAIXADIANA}

Cumpre salientar os percalços de se morar em áreas periféricas, sobretudo para os trabalhadores, a qual "[...] reflete com maior crueza as desigualdades desencadeadas a partir do núcleo metropolitano" (PACHECO, 1984, p. 19), de tal sorte que morar em uma favela carioca é diferente de morar em um "aglomerado subnormal" da Baixada Fluminense, tanto no que se refere ao acesso aos postos de trabalho, quanto no acesso ao consumo de bens e serviços. Isso porque "[...] o território metropolitano fluminense se caracteriza, portanto, pela nítida projeção das linhas de divisão da sociedade fluminense, de tal forma que morar em um lugar ou outro da metrópole não é indiferente" (RIBEIRO; RODRIGUES; CORREA, 2013, p. 171) e neste sentido, Santos (2014, p. 107) lembra que "[...] cada homem vale pelo lugar onde está: o seu valor como produtor, consumidor, cidadão depende de sua localização no território. Seu valor vai mudando incessantemente, para melhor ou para pior, em função das diferenças de acessibilidade (tempo, frequência, preço)".

O ponto do território no qual se localiza o trabalhador baixadiano na lógica espacial da RMRJ the impõe alguns entraves para acessar os postos de trabalhos localizados, preferencialmente, no núcleo metropolitano. Nesse sentido, os dados referentes ao Censo Demográfico de 2010 (IBGE, 2010) apontam o elevado percentual de trabalhadores que gastam mais de uma hora para chegar aos seus locais de trabalho. Em Japeri, mais da metade da força trabalhadora local necessita de um deslocamento superior a uma hora para realizar o trajeto casa-trabalho. Em Queimados esse total chega a 47\% e em Belford Roxo 43\%, conforme registra a Tabela 3.

De acordo com os dados da tabela 3 , apenas $2 \%$ da força de trabalho do município carioca se desloca para outros municípios para exercer sua atividade laboral. No outro extremo, em Mesquita, $60 \%$ da sua população ocupada trabalha fora dos limites municipais. Em Belford Roxo, Japeri, Nilópolis e Queimados, o percentual de população trabalhadora que se desloca para outro munícipio é igual ou superior a $50 \%$. Convém ressaltar que quanto mais tempo o trabalhador necessita para o seu deslocamento, mais recurso ele despende no transporte público e menos tempo Ihe sobra para seu descanso e lazer e para se qualificar.

Como reflexo dessa condição, alguns municípios baixadianos apresentam dados educacionais baixos no contexto metropolitano fluminense. Segundo dados referentes ao ano de 2013 do mapa da desigualdade metropolitana de 2017 (CASA FLUMINENSE, 2017), enquanto a porcentagem de pessoas com ensino médio completo em Niterói era de $66 \%$ e 
no Rio de Janeiro $54 \%$, em Japeri apenas $27 \%$ de sua população tinha completado essa etapa escolar, 31\% em Belford Roxo e 32\% em Queimados e Guapimirim, os menores indicadores da Baixada Fluminense. O melhor resultado foi verificado em Nilópolis com $51 \%$.

Tabela 3 - Dados socioeconômicos dos municípios da Baixada Fluminense (trabalho e renda)

\begin{tabular}{|c|c|c|c|c|}
\hline Municípios & $\begin{array}{l}\text { Pessoas que } \\
\text { trabalhavam fora } \\
\text { do município de } \\
\text { residência - Censo } \\
\text { (2010) }\end{array}$ & $\begin{array}{l}\text { Pessoas que } \\
\text { demoravam mais de } \\
\text { uma hora no trajeto } \\
\text { casa-trabalho - } \\
\text { Censo (2010) }\end{array}$ & $\begin{array}{l}\text { Pessoas que } \\
\text { trabalhavam sem } \\
\text { registro formal - } \\
\text { Censo (2010) }\end{array}$ & $\begin{array}{l}\text { Renda } \\
\text { mensal } \\
\text { per capita } \\
\text { - IPCA } \\
2015\end{array}$ \\
\hline $\begin{array}{l}\text { Belford } \\
\text { Roxo }\end{array}$ & $52 \%$ & $43 \%$ & $41 \%$ & $\mathrm{R} \$ 710$ \\
\hline $\begin{array}{l}\text { Duque de } \\
\text { Caxias }\end{array}$ & $30 \%$ & $32 \%$ & $39 \%$ & $\mathrm{R} \$ 856$ \\
\hline Guapimirim & $22 \%$ & $17 \%$ & $53 \%$ & $\mathrm{R} \$ 858$ \\
\hline Itaguaí & $17 \%$ & $9 \%$ & $40 \%$ & $\mathrm{R} \$ 917$ \\
\hline Japeri & $55 \%$ & $54 \%$ & $46 \%$ & $\mathrm{R} \$ 607$ \\
\hline Magé & $30 \%$ & $29 \%$ & $48 \%$ & $\mathrm{R} \$ 819$ \\
\hline Mesquita & $60 \%$ & $33 \%$ & $42 \%$ & $\mathrm{R} \$ 924$ \\
\hline Nilópolis & $52 \%$ & $33 \%$ & $37 \%$ & $\mathrm{R} \$ 1090$ \\
\hline Nova Iguaçu & $36 \%$ & $39 \%$ & $43 \%$ & $\mathrm{R} \$ 853$ \\
\hline Paracambi & $19 \%$ & $18 \%$ & $45 \%$ & $\mathrm{R} \$ 838$ \\
\hline Queimados & $50 \%$ & $47 \%$ & $41 \%$ & $\mathrm{R} \$ 699$ \\
\hline $\begin{array}{l}\text { São João de } \\
\text { Meriti }\end{array}$ & $49 \%$ & $33 \%$ & $38 \%$ & $\mathrm{R} \$ 863$ \\
\hline Seropédica & $29 \%$ & $23 \%$ & $46 \%$ & $\mathrm{R} \$ 873$ \\
\hline $\begin{array}{l}\text { Rio de } \\
\text { Janeiro }\end{array}$ & $2 \%$ & $26 \%$ & $34 \%$ & $R \$ 2155$ \\
\hline
\end{tabular}

A baixa qualificação média de sua população aliada ao baixo dinamismo econômico verificado em alguns municípios, favorece a criação de postos de trabalhos precários e de baixa remuneração. Essa realidade é exposta na Tabela 3 quando informa que o índice de trabalhadores informais em todos os municípios baixadianos é superior ao verificado no núcleo metropolitano e que a renda mensal per capita de sua população é, no comparativo menos extremo com Nilópolis, praticamente a metade do aferido para a capital fluminense. Em comparação a Japeri, a renda mensal per capita do Rio de Janeiro é 3,5 vezes maior que a do município periférico. Esses dados expõem o caráter econômico altamente concentrador do Rio de Janeiro na Região Metropolitana na qual ele está inserido. 
Esse quadro concentrador verificado na RMRJ associado ao perfil demográfico da Baixada Fluminense - o qual, por sua vez, historicamente é resultado dos interesses dos proprietários fundiários em acordo com o poder público - contribuiu para que esta subregião metropolitana tivesse sua configuração territorial distinta em relação ao núcleo metropolitano. Entre essas diferenciações, a violência consiste na mais emblemática. Com efeito, o Instituto de Segurança Pública (ISP) regionaliza o estado em quatro grandes regiões. Cabe ressaltar que, embora a Baixada Fluminense não exista oficialmente enquanto Região Administrativa de governo, quando a Secretaria de Segurança Pública a institui como uma região, tal fato assinala que sua existência só ganha contornos de "realidade" se entendida a partir das atrocidades criminais que vitimizam seus moradores. Desse modo, a violência oficializa esta região para os órgãos governamentais.

Todavia, embora para a Secretaria de Segurança Pública o entendimento de Baixada Fluminense passe, inequivocamente, pela questão da violência, as políticas públicas ofertadas a essa sub-região metropolitana expõem uma distinção estratégica clara quando comparada ao núcleo metropolitano. Essa diferença se reflete na geografia das UPPs (Unidades de Polícia Pacificadora) e na distribuição de agentes de segurança entre os batalhões da RMRJ. Em 2018, das 37 favelas que contavam com a instalação de UPPs, 36 estavam situadas nos limites do município do Rio de Janeiro e apenas uma estava instalada em um município da Baixada Fluminense, a UPP do Complexo da Mangueirinha, em Duque de Caxias. Em relação ao efetivo policial, enquanto na capital havia um policial para cada 800 residentes em 2018, e nos demais municípios metropolitanos um para cada 883 , a Baixada Fluminense contava com um policial para cada 1.131 moradores (ALBUQUERQUE, 2019).

Os dados sobre a violência metropolitana até 2019 expressam numericamente as implicações dessas políticas desiguais no contexto da RMRJ. Para empreender essa análise, selecionamos três índices: letalidade, homicídio doloso e autos de resistência. Em alguma medida, as taxas de letalidade sintetizam as tipologias de violência existentes em um recorte espacial ao destacar as agressões que produzem óbitos. Nela estão inclusos os dados referentes aos homicídios dolosos, homicídios decorrentes de oposição à intervenção policial, latrocínio (roubo seguido de morte) e lesão corporal seguida de morte. A análise desses dados expõe claramente o desnível entre a Baixada Fluminense e as demais Grandes Regiões de Segurança Pública do Estado do Rio de Janeiro. Desde que a série histórica passou a considerar os dados da Baixada Fluminense, apenas em 2002 essa região não apresentou os índices mais elevados no tocante às taxas de letalidade no Estado do Rio de Janeiro. No ano seguinte, 2003, essa taxa chegou a 70,4, a segunda maior da história recente do estado - menor apenas que os 75,9 registrado pelo Rio de Janeiro em 1994. Embora a taxa de letalidade violenta na Baixada Fluminense em 2019 tenha 
diminuído sensivelmente no comparativo com o ano anterior, ainda assim esse indicador é o mais elevado do estado, conforme registra o gráfico a seguir (Figura 5).

Figura 5 - Gráfico da taxa de letalidade violenta por grupo de 100 mil habitantes no Estado do Rio de Janeiro (1991-2019)

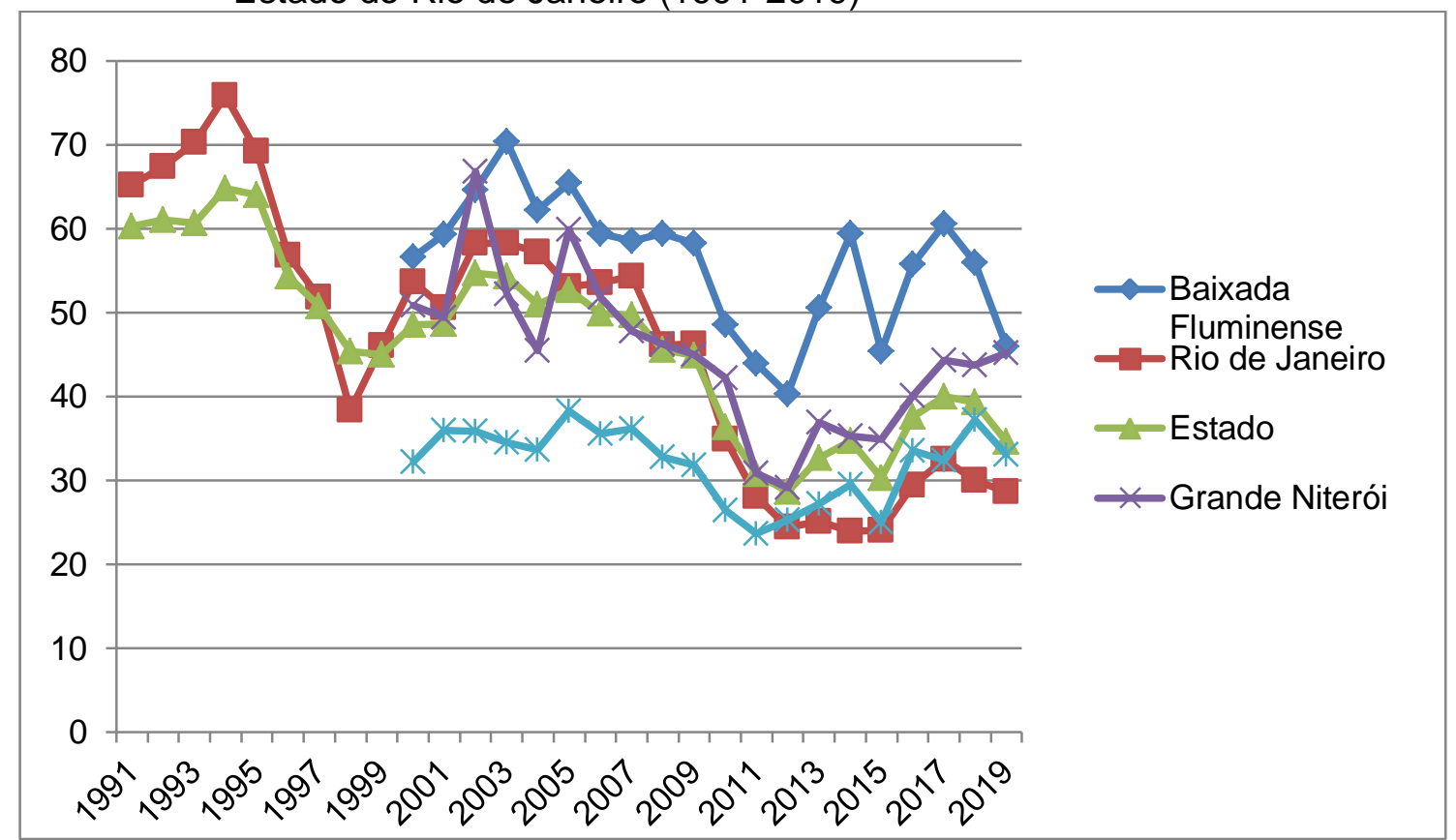

Fonte: Instituto de Segurança Pública (2020).

Em 2014 o município do Rio de Janeiro atingiu sua menor taxa de letalidade desde 1991, enquanto a Baixada Fluminense, nesse mesmo período, apresentou elevação: a taxa saltou de 50,6 em 2013 para 59,4 em 2014. Esse aumento também foi observado na Grande Niterói, outra região que compõe a RMRJ. Esse indicador consiste em um importante dado para se aferir o "grau" de violência existente nos lugares. Considerando essas taxas para o estado do Rio de Janeiro, a Baixada Fluminense é a região que apresenta os dados mais elevados no território fluminense, conforme destacado na Figura 6.

Assim como em relação aos dados relativos à letalidade, cumpre mencionar que as taxas de homicídios dolosos apresentaram uma queda a partir de 2009 , voltando a subir somente em 2016 para o caso do município do Rio de Janeiro. Em contrapartida, essa dinâmica não se verificou na Baixada Fluminense. No período aludido, as taxas de letalidade e de homicídios dolosos inicialmente acompanharam a queda verificada na capital, porém, em 2013, esse indicador aumentou significativamente entre os municípios baixadianos.

A taxa de letalidade atingiu o patamar 59,4 para cada cem mil habitantes em 2014 na Baixada Fluminense. No município do Rio de Janeiro esse número foi de 24,0. Quanto aos homicídios dolosos, nesse mesmo ano a Baixada Fluminense apresentou uma taxa de 52,7, 
enquanto na capital a taxa ficou em 19,2. Parte da explicação para essa distinção verificada no comparativo entre a capital e as demais áreas da RMRJ pode estar relacionada com a política de criação das UPPs iniciadas no fim de 2008.

Figura 6 - Gráfico da taxa de homicídio doloso por grupo de 100 mil habitantes no Estado do Rio de Janeiro (1991-2019)

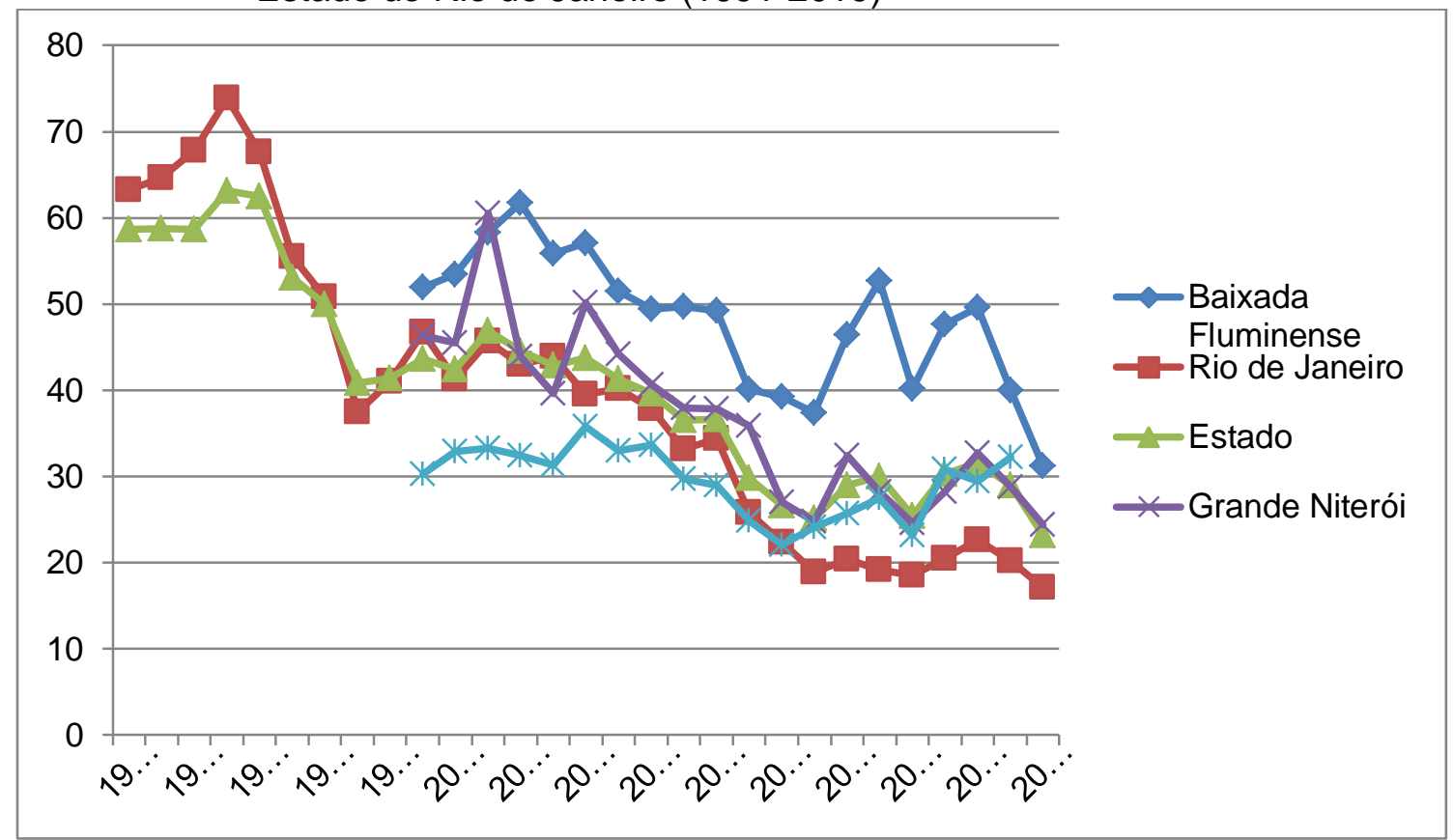

Fonte: Instituto de Segurança Pública (2020).

De acordo com dados do 10 Anuário Brasileiro de Segurança Pública de 2016, entre as 27 capitais da federação, o Rio de Janeiro ocupava 23ำ posição no ranking da violência nacional (FÓRUM BRASILEIRO DE SEGURANÇA PÚBLICA, 2016). A despeito desse dado e da disparidade criminal entre a Baixada Fluminense e a capital, a intervenção federal na área da segurança pública, iniciada em 16 de fevereiro de 2018 e finalizada em 31 de dezembro daquele ano, despendeu efetivo mais numeroso de agentes e ações no município do Rio de Janeiro, a qual contou com 490 operações policiais no âmbito desta intervenção.

As áreas dos municípios baixadianos objeto de operação policial foram majoritariamente apenas os municípios perpassados pela rodovia Presidente Dutra. De acordo com dados do Centro de Estudos de Segurança e Cidadania (CESeC), Duque de Caxias e São João de Meriti totalizaram 67 operações policiais das 106 realizadas na Baixada Fluminense. Desse modo, esses dois municípios isoladamente concentraram $64,0 \%$ das operações na sub-região (RAMOS, 2019). Nilópolis, município que não dispõe de nenhuma rodovia, não teve registrada nenhuma incursão policial no período da intervenção federal. Esses dados sugerem que tal escolha se deveu mais à posição geográfica dos municípios do que propriamente à proteção de seus moradores. Dessa forma, ficou evidenciado que os motivadores da intervenção federal estavam relacionados aos 
crescentes índices de roubos de cargas e aos constantes fechamentos de rodovias, algumas delas vitais para a dinâmica econômica da metrópole.

Alia-se, ao descaso dessas políticas públicas perpetradas pelo estado fluminense e pela União, o fato de essa região sofrer com a violência de grupos paramilitares, expresso pelo elevado número de homicídios e pela repressão do aparato oficial, expresso pelos autos de resistência - apesar de ter um número populacional total equivalente a $58,0 \%$ de sua capital, em 2018 foram registrados 545 autos de resistência em municípios baixadianos contra 556 casos na cidade do Rio de Janeiro. Esses fatores atuam decisivamente para a construção da Baixada Fluminense como lócus puro de violência, como território do medo por excelência.

Considerando o processo de ocupação populacional baixadiano, na primeira fase a violência estava amparada em questões latifundiárias e visava uma ampliação da propriedade e, no limite, impunha um território. A segunda fase marca um momento no qual a violência se dissemina como uma manifestação político-territorial mais clara. Tortura e execuções de bandidos e comunistas demarcaram a Baixada Fluminense como território de grupos paramilitares apoiadas pelo regime de exceção a partir do golpe militar de 1964 . Na terceira fase, iniciada com a Nova República e compreendendo o período atual, os agentes executores da violência sofisticam sua atuação e passam a compor diretamente os poderes legislativo e executivo, seja de forma direta ou por intermédio de pessoas ligadas aos seus interesses (ALVES, 2003). Com efeito, na Baixada Fluminense ocorreu a "politização" da violência, de modo que os mecanismos de repressão foram convertidos em instrumentos políticos.

A politização da violência na região guarda estreita relação com as ineficientes ações governamentais na área da segurança pública. Essa ineficiência atinge também a área cultural da Baixada Fluminense. A análise espacial dos equipamentos culturais mantidos pelo governo do Estado do Rio de Janeiro indica claramente a geografia desigual da prestação desse tipo de serviços voltados ao lazer considerando o estado como um todo e o interior da RMRJ. A Fundação Anita Mantuano de Artes do Estado do Rio de Janeiro (FUNARJ) é uma autarquia responsável pela gestão de alguns espaços públicos do governo do estado. A essa fundação, de acordo com seu site institucional (FUNDAÇÃO DE ARTES DO ESTADO DO RIO DE JANEIRO, 2020), compete a gestão de 18 equipamentos públicos entre centros culturais, museus e teatros. Embora a construção de um fixo cultural não redunde, necessariamente, em atividades culturais naquele espaço, uma vez que grande parte deles se encontram fechados ou subutilizados, o fato é que entre os 18 equipamentos mantidos pela Funarj, dois estão localizados no interior do Estado, um no município de Casimiro de Abreu (Baixadas Litorâneas) e outro em Cantagalo (Região Serrana). Dentre os 
16 equipamentos culturais localizados na RMRJ, 13 estão na capital e os outros três restantes no município de Niterói.

A Baixada Fluminense, mesmo sendo composta por 13 municípios com uma população superior a três milhões de habitantes, não conta atualmente com nenhum equipamento cultural do governo estadual. Em contrapartida, a Zona Sul do Rio de Janeiro, com uma população cinco vezes menor que a Baixada Fluminense, é contemplada com seis espaços culturais. A diferenciação no tocante ao consumo desses bens culturais se relaciona, também, com uma escolha política. A presença de espaços culturais privados próximos à população de renda mais elevada se explica pela lógica do mercado, já a concentração desses mesmos espaços culturais de gestão pública nessa área de renda mais elevada não encontra nenhuma explicação do ponto de vista social que objetive a construção de um Estado menos desigual. Pelo contrário, o Estado não atua no sentido de minimizar as disparidades, mas as acirra quando dota algumas áreas de equipamentos culturais em detrimento de outras áreas.

Amparadas em grande medida pela inação estatal, seja quanto ao planejamento urbano, passando pela atuação na área da segurança pública até a gestão cultural, "[...] mais que um substantivo próprio que possui a função de nomear; atribui-se à 'Baixada' uma ideia 'qualificadora', quase que adjetivada, associada às noções de miséria, fome, violência, grupos de extermínio, periferia, lugar distante etc. (ROCHA, 2013, p. 145). Nesse sentido, toda essa construção material associada à Baixada Fluminense acaba a conduzindo para a construção de uma geografia imaginativa, a qual, de acordo com Driver (2005, p. 144), são “[...] representações de lugares que estruturam o entendimento de mundo das pessoas e consequentemente ajudam a moldar suas ações". Nesse sentido, a geografia imaginativa referente à Baixada Fluminense a associa a atraso socioeconômico, violência e carências de múltiplas naturezas. Dessa maneira, o espaço é simultaneamente imaginário e material e, devido a essa condição, toda construção imaginativa (ideologia) é capaz de produzir materialidade.

\section{CONSIDERAÇÕES FINAIS}

O processo de ocupação populacional da Baixada Fluminense encetado a partir das demandas socioeconômicas do município do Rio de Janeiro se efetivou de modo atabalhoado para o espaço baixadiano. As populações foram alocando-se em propriedades com notáveis deficiências, originárias de loteamentos privados, os quais posteriormente foram recebendo intervenções públicas. As mazelas sociais que hoje afligem alguns municípios baixadianos não podem ser imputadas à eventual predileção dada à capital nas formulações de políticas públicas. Entretanto, o entendimento referente ao processo 
histórico de ocupação populacional da região, sua importância e configuração socioeconômica no momento atual, só têm sentido se compreendidos no âmbito da RMRJ. Como efeito dessa retroalimentação, o papel desempenhado pelo município do Rio de Janeiro na conjuntura nacional e internacional reflete o papel imposto à Baixada Fluminense na conjuntura metropolitana.

Apesar desse vínculo, as questões que assolam a Baixada Fluminense parecem não ter relação com o Rio de Janeiro. Desse modo, a RMRJ existe como realidade econômica por meio dos fluxos econômicos e de trabalhadores, contudo problemas como a violência parece dizer respeito somente aos municípios baixadianos. É como se fosse outro espaço, externo e longínquo composto por outra "categoria" de pessoas. Essa construção simbólica, eivada de geografia imaginativa, singulariza a Baixada Fluminense como um território produzido e condicionado a partir de suas carências.

Como arremate da questão em tela, queremos ressaltar que em uma região metropolitana, na qual o fluxo entre suas partes integrantes é intenso, o núcleo naturalmente concentra a maior parte dos postos de trabalho. Por essa razão, o fortalecimento das políticas de segurança no município do Rio de Janeiro e o seu desenvolvimento econômico, em alguma medida, beneficiam o morador da Baixada Fluminense. Contudo, não apenas sua condição de reprodutor do sistema econômico, expresso na categoria de trabalhador, deve ser protegida. Antes de fazer a roda econômica girar, o morador da Baixada Fluminense necessita fazer sua vida acontecer, pois mesmo sendo peça central da maquinaria capitalista, ele é insubstituível para seus entes e amigos e essa condição deve, também, ser objeto de ações públicas de segurança por parte do Estado.

\section{REFERÊNCIAS}

ABREU, Maurício de Almeida. Evolução urbana do Rio de Janeiro. Rio de Janeiro: IPP, 2010.

ALBUQUERQUE, Enderson Alceu Alves. "Votar em Rei dá Abraão”: identidade e poder na Baixada Fluminense a partir da Beija-Flor de Nilópolis. 2019. Tese (Doutorado em Geografia) - Instituto de Geografia, Universidade do Estado do Rio de Janeiro, Rio de Janeiro, 2019.

ALVES, José Cláudio Souza. Dos Barões ao extermínio: uma história da violência na Baixada Fluminense. Duque de Caxias, RJ: APPH-CLIO, 2003.

ÁREA para loteamento. Jornal O Globo, Rio de Janeiro, RJ, 21 dez. 1953. Caderno de classificados, p. 7.

CASA FLUMINENSE. Mapa da desigualdade 2017. Rio de Janeiro, RJ: Casa Fluminense, 2017. Disponível em: file:///C:/Users/ender/Desktop/PDF\%20-

\%20Casa\%20Fluminense\%20(2).pdf. Acesso em: 5 maio 2020.

CORRÊA, Roberto Lobato. Trajetórias geográficas. Rio de Janeiro: Bertrand Brasil, 2011.

CRISE de mercado atinge loteamentos da Baixada. Jornal do Brasil, Rio de Janeiro, RJ, 4 nov. 1973. Caderno RJ, p. 1. 
DRIVER, Felix. Imaginative geographies. In: CLOKE, Paul; CRANG, Philip; GOODWIN, Mark. (org.). Introducing human geographies. London: Arnold, 2005. p. 234-248.

FIGUERÊDO, Maria Aparecida de. A. Gênese e (re) produção do espaço brasileiro na Baixada Fluminense. Revista geo-paisagem (online), Rio de Janeiro, RJ, ano 3, n. 5, jan. /jun. 2004. Disponível em: http://www.feth.ggf.br/Baixada.htm. Acesso em: 5 maio 2020. FÓRUM BRASILEIRO DE SEGURANÇA PÚBLICA. Anuário Brasileiro de Segurança Pública, São Paulo, SP, ano 10, 2016. Disponível em:

www.forumseguranca.org.br/storage/10_anuario_site_18-11-2016-retificado.pdf. Acesso em: 21 jul. 2020.

FUNDAÇÃO DE ARTES DO ESTADO DO RIO DE JANEIRO - FUNARJ. Espaços Culturais. Rio de Janeiro, RJ: Secretaria de Estado de Cultura e Economia Criativa/ FUNARJ, 2020. Disponível em: http://www.funarj.rj.gov.br/espaco/. Acesso em: 7 ago. 2020.

FUNDAÇÃO PARA O DESENVOLVIMENTO DA REGIÃO METROPOLITANA DO RIO DE JANEIRO - FUNDREM. Unidades urbanas integradas de oeste: plano diretor. Rio de Janeiro, RJ: FUNDREM, 1979.

GÓES, Hildebrando de Araujo. Relatório apresentado pelo engenheiro chefe da Comissão de Saneamento da Baixada Fluminense. Rio de Janeiro, RJ: Ministério da Viação e Obras Públicas, 1934.

HOMENAGEADO o Bandeirante da Baixada Fluminense. Jornal O Globo, Rio de Janeiro, RJ, p. 6, 17 set. 1951.

IBGE. Censo demográfico. Rio de Janeiro, RJ: IBGE, 1920. Disponível em: www.ibge.gov.br. Acesso em: 25 set. 2017.

IBGE. Censo demográfico. Rio de Janeiro, RJ: IBGE, 1940. Disponível em: www.ibge.gov.br. Acesso em: 25 set. 2017.

IBGE. Censo demográfico. Rio de Janeiro, RJ: IBGE, 1950. Disponível em: www.ibge.gov.br. Acesso em: 25 set. 2017.

IBGE. Censo demográfico. Rio de Janeiro, RJ: IBGE, 1970. Disponível em: www.ibge.gov.br. Acesso em: 25 set. 2017.

IBGE. Censo demográfico. Rio de Janeiro, RJ: IBGE, 1980. Disponível em: www.ibge.gov.br. Acesso em: 25 set. 2017.

IBGE. Censo demográfico. Rio de Janeiro, RJ: IBGE, 1991. Disponível em: www.ibge.gov.br. Acesso em: 25 set. 2017.

IBGE. Censo demográfico. Rio de Janeiro, RJ: IBGE, 2000. Disponível em: www.ibge.gov.br. Acesso em: 25 set. 2017.

IBGE. Censo demográfico. Rio de Janeiro, RJ: IBGE, 2010. Disponível em: www.ibge.gov.br. Acesso em: 25 set. 2017.

IBGE. Censo demográfico. Rio de Janeiro, RJ: IBGE. 1960. Disponível em: www.ibge.gov.br. Acesso em: 25 set. 2017.

INSTITUTO DE SEGURANÇA PÚBLICA - ISP. Séries históricas anuais de taxa de letalidade violenta no Estado do Rio de Janeiro e grandes regiões. Rio de Janeiro, RJ: ISP-RJ, 2020. Disponível em:

http://www.ispdados.rj.gov.br/Arquivos/SeriesHistoricasLetalidadeViolenta.pdf. Acesso em: 30 mar. 2020.

LAGO, Luciana Corrêa. Desigualdades e segregação na metrópole: o Rio de Janeiro em tempo de crise. Rio de Janeiro: Revan, 2000. 
LAMEGO, Alberto Ribeiro. O homem e a Guanabara. Rio de Janeiro: Biblioteca Geográfica Brasileira/IBGE, 1964.

MERCADO de imóveis. Jornal O Globo, Rio de Janeiro, RJ, 18 out. 1945. Caderno de classificados, p. 2.

PACHECO, Susana Mara Miranda. Produção e reprodução de loteamentos na periferia do Rio de Janeiro. 1984. Tese (Doutorado em Geografia Humana) - Instituto de Geociências, Universidade Federal do Rio de Janeiro, RJ, Rio de Janeiro, 1984.

RAMOS, Silvia (coord.). Intervenção federal: um modelo para não copiar. Rio de Janeiro, RJ: CESeC, 2019.

RIBEIRO, Luiz Cesar de Queiroz.; RODRIGUES, Juciano Martins; CORREA, Filipe Souza. Território e trabalho: segregação e segmentação urbanas e oportunidades ocupacionais na região metropolitana do Rio de Janeiro. In: SANTOS, Angela Moulin S. Penalva; MARAFON, Glaucio José; SANT'ANNA, Maria Josefina Gabriel. Rio de Janeiro: um olhar socioespacial. Rio de Janeiro: Grama, 2013. p. 169-198.

ROCHA, André Santos da. Baixada Fluminense: representações espaciais e disputas de legitimidades na composição territorial municipal. 2009. Dissertação (Mestrado em Geografia) - Universidade Federal Fluminense, Niterói, RJ, 2009.

ROCHA, André Santos da. Território como representação. Mercator, Fortaleza, CE, v. 12, n. 29, p. 139-153, set. /dez. 2013.

SANTOS, Milton. O espaço do cidadão. São Paulo: Edusp, 2014.

SEGADAS SOARES, Maria Therezinha de. Nova Iguaçu: absorção de uma célula urbana pelo grande Rio de Janeiro. Revista Brasileira de Geografia, Rio de Janeiro, RJ, ano 24, n. 2, p. 157-241, abr./ jun. 1962.

SIMÕES, Manoel Ricardo. A cidade estilhaçada: reestruturação econômica e emancipações municipais na Baixada Fluminense. Mesquita, RJ: Entorno, 2008.

SOUTO, Adriana Branco Correia. As comissões federais de saneamento da Baixada Fluminense (1910/1933). 2016. Dissertação (Mestrado em Desenvolvimento Territorial) Instituto de Ciências Sociais e Aplicadas, Universidade Federal Rural do Rio de Janeiro, Nova Iguaçu, RJ, 2016.

VALORIZAÇÃO e aproveitamento do campo para a salvação das cidades! Jornal O Globo, Rio de Janeiro, RJ, p. 7, 22 jul. 1952.

Recebido: junho de 2020. Aceito: agosto de 2020. 